\title{
Isolated Medial Talonavicular Dislocation: A Case Report
}

Smail Abdouli ${ }^{1,2}$, Amour Espoir Mokoko-Louckou ${ }^{2}$, Chaibou Badarou ${ }^{2}$, Mohammed Elidrissi Abdelhalim Elibrahimi ${ }^{2}$, Abdelmajid Elmrini ${ }^{2}$, Omar kada ${ }^{1}$

${ }^{1}$ Orthopedic Department, Gonesse Hospital Center, 2 Boulevard du 19 Mars 1962, 95500 Gonesse, France

${ }^{2}$ Orthopedic Department, UHC HassanII, University Sidi Mohmmed Ben Abdellah, 3000 fez, Morocco

DOI: $10.36347 /$ sjams.2020.v08i06.018

| Received: 31.05.2020 | Accepted: 09.06.2020 | Published: 20.06.2020

*Corresponding author: Smail Abdouli

\section{Abstract}

Dislocation of the talonavicular joint is rare. We report a case of isolated Medial talonavicular dislocation in a 46 year old man. A closed reduction has been performed, followed of 6 weeks in a casting. After 18 years of follow-up, none complications have been reported.

Keywords: Isolated talonavicular dislocation.

Copyright @ 2020: This is an open-access article distributed under the terms of the Creative Commons Attribution license which permits unrestricted use, distribution, and reproduction in any medium for non-commercial use (NonCommercial, or CC-BY-NC) provided the original author and source are credited.

\section{INTRODUCTION}

Talonavicular joint dislocation without subtalar joint dislocation or tarsal bones fracture is rare. This rarity is explained by the stability conferred by the geometry and orientation of the tarsal bones which are firmly united by a robust ligament system. We discuss through our observation and a review of the literature the mechanisms of injury, and the therapeutic options for this injury.

\section{Case Report}

A 49 year old man presented to the Emergency Department for a trauma to the right foot following a fall from stairs at work using a plantar hyperflexion mechanism. The patient complained of pain along the medial aspect of the talonavicular joint. Physical examination revealed a deformed swollen over the dorsum her right foot without skin opening. He was unable to plantarflex his ankle. There was no neurovascular deficit. Xray revealed isolated Medial talo-navicular dislocation [Figures 1(a) and 1(b)]. the computed tomography scan and $3 \mathrm{D}$ reconstruction of right foot revealed medial dislocation of talonavicular joint without associated fracture [Figures 2(a) and 2(b)].
The decision was made to perform a closed reduction in the operating room. The patient was placed under conscious sedation and the dislocation was manually reduced by first placing the knee in 90 degrees of flexion and plantar-flexing the ankle, thereby relaxing the gastrocnemius-soleus complex, then The porefoot distracting axially with counter pressure proximally and finally reducing the distal foot back into its natural position. It was noted that upon relocation, a pop was felt and the foot appeared realigned relative to the contralateral foot. The neurovascular examination to the foot was normal after reduction. Postreduction radiographs demonstrated a well-reduced talonavicular joint [Figures 3(a) and 3(b)], a computed tomography scan was obtained to delineate better the associated injuries and to assess for congruent reduction. CT showed a congruent reduction of the talonavicular joint without evidence of any intraarticular debris [Figures 4(a) and 4(b)]. The patient was immobilized in a short leg cast for 6 weeks. A vigorous, active exercise program, progressive weightbearing, and active rangeof-motion exercises. After 18 months, the patient had a stable, relatively good functional foot, with minimal pain on walking on uneven ground. 


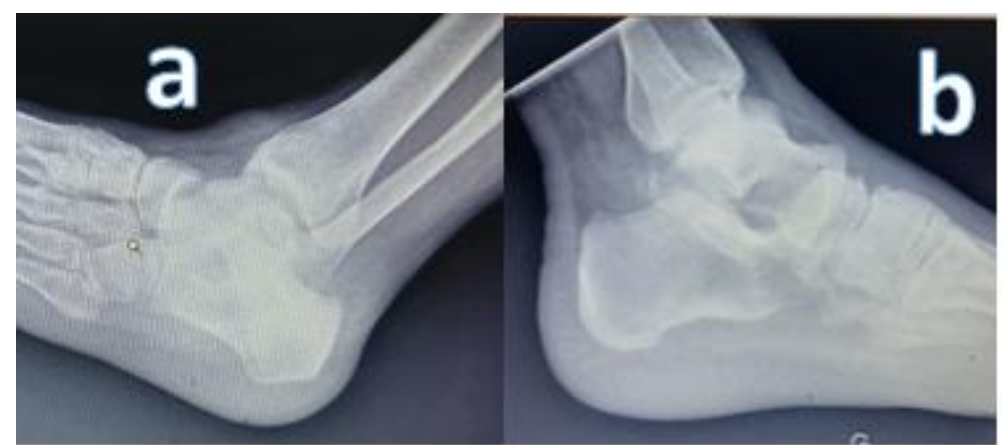

Fig-1: AP and lateral radiographs of the foot showing medial talonavicular dislocation

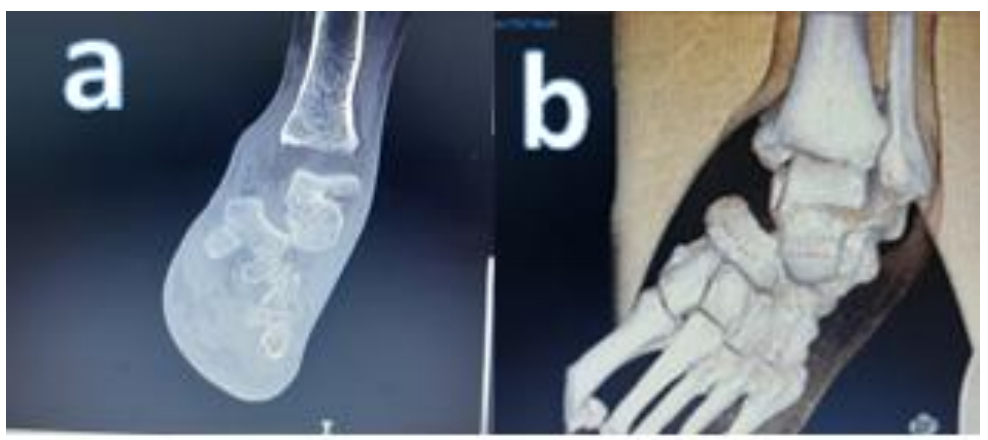

Fig-2: CT scan and 3d reconstruction of the foot showing the dislocation

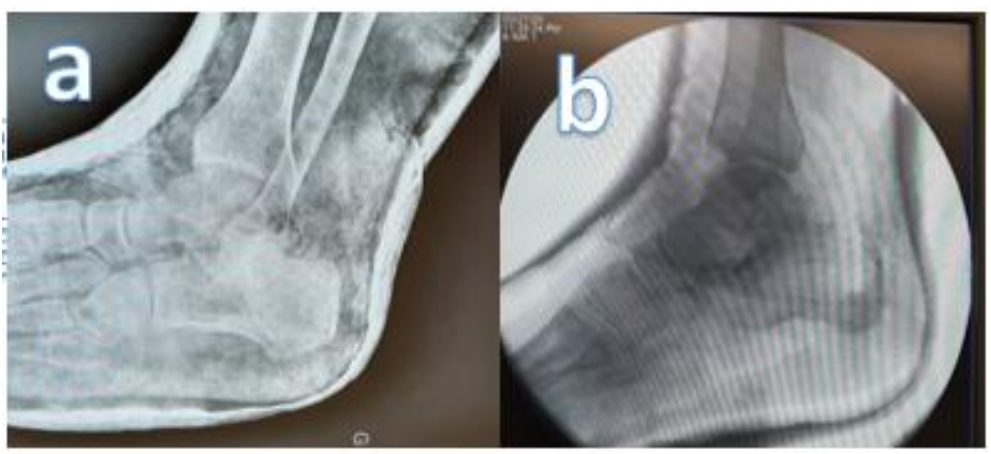

Fig-3: Postreduction radiographs demonstrating congruent of the talonavicular joint.

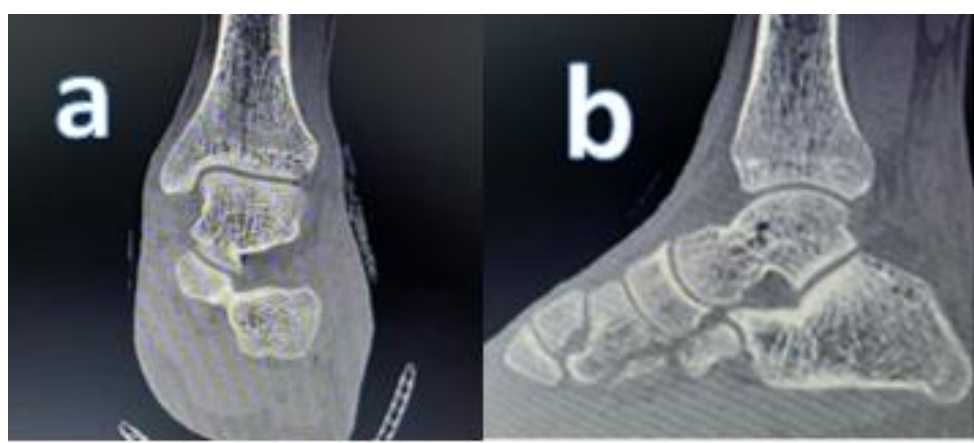

Fig-4: CT scan demonstrating congruent reduction of the talonavicular joint without evidence of any intraarticular debris

\section{DISCUSSION}

Isolated dislocation of the talonavicular joint is rare, caused by severe abduction or adduction of the forefoot and often associated with fractures of the navicular, cuboid, or calcaneus [1]. This joint is less susceptible to injured because of the strong ligamentous structures around them, the strongest ligamentous structures lies on the plantar side which is protected by the long and short plantar ligament, bifurcate ligament, and the spring ligament, which supports the arch of the foot [2]. The most reported mechanism is plantarcompression $[3,4]$ in which the position of the foot and the direction of the trauma will determine the direction of dislocation. Main and Jowett classified midtarsal injuries according to direction of deforming force and displacement into five groups (medial, longitudinal compression, lateral, plantar, and crush) [5]. The diagnosis of tarsal talonavicular dislocation is based on 
the analysis of radiological images of the foot and forefoot in front and profile view. The CT scan specifies the extent of the bone lesions. A threedimensional reconstruction provides a relief representation of the bone parts and allows us to see the type of dislocation and to understand the lesion mechanism. Magnetic resonance imaging (MRI) is useful for diagnosing ligament injuries and evaluating the vascular risk of the bone by specifying the residual insertion of the soft tissue [6]. The aim of the treatment is to obtain a plantigrade foot, maintaining an adequate length of the two columns, while preserving joint mobility at the talo-navicular and cuboid-metatarsal level [7].varied treatment options have been suggested. While the closed reduction was found to be adequate in cases of a sudden dislocation, an open reduction was necessary in cases of late presentation or when the closed reduction was not successful $[8,9]$. Both of these methods have given well to fair functional results. In this report, we preferred the closed reduction with immobilization in a short leg plaster for 6 weeks, the result is satisfactory.

\section{CONCLUSION}

Isolated talonavicular dislocation is rare. It represents a complex lesion of the plantar ligament structures. It is important to recognize this lesion, because early diagnosis and management promote good results. The anatomical and stable reduction can be obtained by using a closed manual reduction associated with an immobilization for a sufficient period and followed by an adapted rehabilitation.

\section{Conflicts of Interest}

None of the authors has any conflict of interest

\section{REFERENCES}

1. Ross PM, Mitchell DC. Dislocation of the talonavicular joint: case report. J Trauma. 1976; 16:397-401.

2. McMinn RMH. Last's anatomy: regional and applied. 8th edition London: Churchill Livingstone. 1990; 204-217.

3. Dhillon MS, Nagi ON. Total dislocation of the navicular: are they ever isolated injuries? J Bone Joint Surg Br.1999;81-B:881-5.

4. Kennedy JG, Maher MM, Stephens MM. Fracture dislocation of the tarsal navicular bone: A case report and proposed mechanism of injury. Foot Ankle Surg.1999;5:167-70.

5. Injuries of the Midtarsal Joint. Main BJ, Jowett RL. JBJS. 1975; 57B:89-97.

6. Preidler KW, Peicha G, Laitai G, Seibert FJ, Fock C, Szolar DM. Conventional radiography, CT, and MR imaging in patients with hyperflexion injuries of the foot: diagnostic accuracy in the detection of bony and ligamentous changes. AJR Am J Roentgenol.1999; 173:1673-7.

7. Rao H. Complete Open Dislocation of the Navicular: A Case Report. Journal of Foot and Ankle Surgery.2012;51(2):209-11.

8. Main BJ, Jowett RL. Injuries to the midtarsal joint. J Bone Joint Surg Br. 1975;57(1):89-97.

9. Verhaar JA. Recurrent medial swivel dislocation of the foot. J Bone Joint Surg Br. 1990;72(1):154-5. 